\title{
Glutamina para frangos de corte criados em ambiente quente
}

\author{
Manvailer, G.V.; Kiefer, C. ${ }^{\circledR}$; Souza, K.M.R. de; Marçal, D.A.; Paiva, L.L.; Rodrigues G.P. e Ozelame, A.M.
}

Universidade Federal de Mato Grosso do Sul (UFMS). Campo Grande. MS. Brasil.

\section{PaLAVRAS CHAVE ADICIONAIS}

Aminoácido não-essencial.

Agentes tróficos.

Características de carcaca.

Desafio sanitário.

Desempenho.

Visceras.

\section{RESUMO}

Realizou-se este estudo com o objetivo de avaliar planos de suplementação de glutamina para frangos de corte, de um a 42 dias de idade, criados em ambiente quente. Utilizou-se 690 pintainhos de corte machos da linhagem Cobb distribuídos em delineamento em blocos casualizados com cinco planos de suplementação de glutamina: $0 \%$ de um a 42 dias de idade; $0,5 \%$ de um a 7 dias e $0 \%$ de 8 a 42 dias; $1,0 \%$ de um a 7 dias e $0 \%$ de 8 a 42 dias; $1,0 \%$ de um a 7 dias, $0,5 \%$ de 8 a 14 dias e $0 \%$ de 15 a 42 dias; $1,0 \%$ de um a 7 dias, $1,0 \%$ de 8 a 14 dias, $0,5 \%$ de 15 a 21 dias e $0 \%$ de 22 a 42 dias e 6 repetições de 23 aves cada. Adotou-se o peso inicial das aves como critério de bloqueamento. Os dados obtidos foram submetidos à análise de covariância e quando ocorreram diferenças significativas as médias foram comparadas pelo teste de Tukey a $5 \%$ de probabilidade. Constatou-se que as aves alimentadas com as dietas suplementadas com $1,0 \%$ de glutamina de um a 14 dias e $0,5 \%$ de glutamina de 14 a 21 dias apresentaram maior peso corporal final, ganho de peso e maiores pesos de carcaça, de peito e de dorso. Para aves criadas sob temperaturas elevadas, recomenda-se a suplementação de glutamina de $1,0 \%$ de um a 14 dias e $0,5 \%$ de 14 a 21 dias e $0 \%$ de 22 a 42 dias de idade, a qual proporciona maior peso corporal, ganho de peso, pesos de carcaça e de peito e rendimento de carcaça.

\section{Glutamine for broilers reared in hot environment}

\section{SUMMARY}

\section{ADDITIONAL KEYWORDS}

Carcass characteristics.

Health challenge.

Offal.

Performance.

Non-essential amino acids.

Trophic agents.

\section{INFORMACIÓN}

\section{Cronología del artículo.}

Recibido/Received: 30.3 .2015

Aceptado/Accepted: 23.9.2015

On-line: 10.12 .2015

Correspondencia a los autores/Contact e-mail:

charles.kiefer@ufms.br

\section{INTRODUÇÃO}

Durante o estresse, a glutamina pode ser essencial para a manutenção da estrutura e função intestinal, sendo utilizada por células isoladas do sistema imune para a proliferação de linfócitos e produção de citocinas. Além disso, sob estresse, a liberação da glutamina pode exceder a síntese no músculo esquelético resultando em redução da concentração intracelular de glutamina aumentando a degradação de proteína (Newsholme, 2001).

Os efeitos positivos da glutamina na alimentação envolvem mudanças morfológicas e fisiológicas como a ação trófica no epitélio intestinal, que podem proporcionar o aumento na área de superfície de digestão e absorção (Yi et al., 2005), melhorando o desempenho principalmente durante o período inicial de desenvolvimento do trato digestório (Yi et al., 2005; Zavarize et 
al., 2011). Contudo, nem sempre os efeitos benéficos sobre a morfologia intestinal gerados pela glutamina resultam em melhora do desempenho das aves (Maiorka et al., 2000; Murakami et al., 2007).

Estudo recente sugere que a suplementação de L-glutamina e L-ácido glutâmico em dietas para frangos de corte, criados sob estresse por calor, podem melhorar o desempenho, a sobrevivência, a morfologia e a atividade de amilase intestinal (Olubodun et al., 2015). Entretanto, estudos relacionando a utilização de glutamina na dieta de frangos de corte em condições de temperaturas ambientais elevadas ainda são escassos. Portanto, realizou-se este estudo com o objetivo de avaliar planos de suplementação de glutamina para frangos de corte, de um a 42 dias de idade, criados em ambiente quente.

\section{MATERIAL E MÉTODOS}

O experimento foi conduzido no Laboratório Experimental em Ciência Aviária, da Faculdade de Medicina Veterinária e Zootecnia, da Universidade Federal de Mato Grosso do Sul, em Campo Grande/MS. Foram utilizados 690 pintainhos de corte, machos de um dia, da linhagem $\mathrm{Cobb}^{\circledR}$ 500, alojados em densidade de 7,7 aves $/ \mathrm{m}^{2}$ e distribuídos em delineamento em blocos casualizados com cinco planos de suplementação de glutamina: $0 \%$ de glutamina de um a 42 dias de idade; $0,5 \%$ de glutamina de um a 7 dias e $0 \%$ de 8 a 42 dias; $1,0 \%$ de glutamina de um a 7 dias e $0 \%$ de 8 a 42 dias; $1,0 \%$ de glutamina de um a 7 dias, $0,5 \%$ de glutamina de 8 a 14 dias e $0 \%$ de 15 a 42 dias; $1,0 \%$ de glutamina de um a 7 dias, 1,0\% de glutamina de 8 a 14 dias, $0,5 \%$ de glutamina de 15 a 21 dias e $0 \%$ de 22 a 42 dias, com 6 blocos considerados repetições de 23 aves cada. Adotou-se o peso inicial das aves como critério de bloqueamento.

O período experimental foi dividido nas fases préinicial (um a 7 dias), inicial (8 a 21 dias), crescimento (22 a 33 dias) e pré-abate (34 a 42 dias). As dietas experimentais (tabela I) foram isoenergéticas e isoproteicas, elaboradas a base de milho e farelo de soja e formuladas para atender as exigências nutricionais recomendadas por Rostagno et al. (2011). A suplementação de glutamina foi realizada pela substituição do caulim pelo produto composto de $95 \%$ de L-glutamina $+5 \%$ de ácido glutâmico (aminogut $\AA$ ), nas concentrações correspondentes aos planos estabelecidos.

As rações e a água foram fornecidas às aves ad $l i$ bitum durante todo o período experimental por meio de comedouros tubulares e bebedouros pendulares. A mortalidade foi monitorada diariamente. Durante o período experimental as aves foram alojadas em cama reutilizada de seis lotes anteriores, obtida de criadores comerciais de frangos de corte da região.

O programa de luz adotado foi o de iluminação natural durante o dia e artificial durante a noite totalizando 24 horas de luz diária durante todo período experimental. A temperatura e umidade relativa foram monitoradas diariamente às 07 e 17 horas por meio de termômetro digital de máxima e mínima, termohigrômetro e termômetro de globo negro que foram
Tabela I. Composições centesimal e nutricional das dietas experimentais (Centesimal and nutritional compositions of the experimental diets).

\begin{tabular}{|c|c|c|c|c|}
\hline \multirow{2}{*}{ Ingredientes (\%) } & \multicolumn{4}{|c|}{ Dietas } \\
\hline & $\mathrm{PI}$ & I & $\mathrm{C}$ & $\mathrm{T}$ \\
\hline Milho & 52,98 & 55,82 & 58,72 & 62,00 \\
\hline Farelo de soja, $45 \%$ & 39,33 & 36,21 & 32,63 & 29,61 \\
\hline Óleo de soja & 2,51 & 3,35 & 4,26 & 4,35 \\
\hline Fosfato bicálcico & 1,90 & 1,50 & 1,33 & 1,12 \\
\hline $\begin{array}{l}\text { Caulim/(L-glutamina_L-ácido } \\
\text { glutâmico) }\end{array}$ & 1,00 & 1,00 & 1,00 & 1,00 \\
\hline Calcário calcítico & 0,88 & 0,87 & 0,86 & 0,77 \\
\hline Sal comum & 0,47 & 0,44 & 0,42 & 0,41 \\
\hline L-lisina $\mathrm{HCl}$ & 0,28 & 0,24 & 0,24 & 0,24 \\
\hline DL-metionina & 0,34 & 0,29 & 0,27 & 0,24 \\
\hline L-treonina & 0,11 & 0,08 & 0,07 & 0,06 \\
\hline Suplemento mineral ${ }^{1}$ & 0,10 & 0,10 & 0,10 & 0,10 \\
\hline Suplemento vitamínico ${ }^{2}$ & 0,10 & 0,10 & 0,10 & 0,10 \\
\hline Total & 100,00 & 100,00 & 100,00 & 100,00 \\
\hline
\end{tabular}

Valores calculados

\begin{tabular}{lrrrr}
\hline Energia metabolizável (Kcal/kg) & 2.960 & 3.050 & 3.150 & 3.200 \\
Proteína bruta (\%) & 22,48 & 21,20 & 19,80 & 18,66 \\
Met+cist. digestível (\%) & 0,95 & 0,88 & 0,83 & 0,77 \\
Lisina digestível (\%) & 1,32 & 1,21 & 1,13 & 1,06 \\
Treonina digestível (\%) & 0,86 & 0,79 & 0,74 & 0,69 \\
Arginina digestível (\%) & 1,43 & 1,34 & 1,24 & 1,55 \\
Triptofano digestível (\%) & 0,25 & 0,24 & 0,22 & 0,21 \\
Cálcio (\%) & 0,92 & 0,84 & 0,76 & 0,66 \\
Fósforo disponível (\%) & 0,47 & 0,41 & 0,35 & 0,31 \\
Sódio (\%) & 0,22 & 0,21 & 0,20 & 0,19 \\
Cloro (\%) & 0,20 & 0,19 & 0,18 & 0,17 \\
Potássio (\%) & 0,59 & 0,59 & 0,58 & 0,58
\end{tabular}

$\mathrm{PI}=$ Pré-inicial; I= Inicial; C= Crescimento; $\mathrm{T}=$ Terminação. ${ }^{1}$ Níveis por kg de ração. Suplemento mineral: $11,00 \mathrm{mg}$ zinco; $3,04 \mathrm{mg}$ ácido pantotênico; 0,22 mg iodo; 0,06 mg selênio; $90 \mathrm{mg}$ colina; $8,48 \mathrm{mg}$ ferro; 2,64 mg cobre; 15,15 mg manganês. ${ }^{2}$ Níveis por kg de ração. Suplemento vitamínico: 2400 UI vitamina $A ; 480$ UI vitamina $D_{3} ; 0,32$ $\mathrm{mg}$ vitamina $\mathrm{K} 3 ; 0,51 \mathrm{mg}$ vitamina $B 1 ; 1,38 \mathrm{mg}$ vitamina $B_{2} ; 0,64 \mathrm{mg}$ vitamina $B_{6} ; 2,88$ mg vitamina $B_{12} ; 3,00$ mg vitamina $E ; 7,12$ mg niacina.

instalados no centro do galpão em um boxe vazio na altura do corpo das aves. Os dados foram utilizados para calcular o ITGU (índice de temperatura de globo e umidade) do ambiente.

Durante o período experimental as temperaturas médias (máxima e mínima), de globo negro e umidade relativa do ar foram de $34,7^{\circ} \mathrm{C} ; 24,48^{\circ} \mathrm{C} ; 30,31^{\circ} \mathrm{C}$ e $71,5 \%$, respectivamente. O ITGU calculado de um a 21 dias foi de 80,3 e de um a 42 dias foi de 80,2 o que caracteriza o ambiente térmico como de estresse por calor (Furtado et al., 2003).

As aves e as sobras de ração foram pesadas semanalmente para determinação do peso corporal final, ganho de peso, consumo de ração, conversão alimentar e viabilidade criatória, nos períodos de um a 21 e um a 42 dias. A determinação da viabilidade produtiva foi obtida pela seguinte fórmula: Viabilidade produtiva= [(número de aves alojadas - número de aves mortas) / número de aves alojadas] ${ }^{*} 100$. 
Tabela II. Desempenho de frangos de corte no período de 1 a 21 e de 1 a 42 dias de idade submetidos a diferentes planos de suplementação de glutamina (Broiler performance in the period 1-21 and 1-42 days of age under different glutamine supplementation plans).

\begin{tabular}{|c|c|c|c|c|c|c|c|}
\hline \multirow{3}{*}{ Variáveis } & \multicolumn{5}{|c|}{ Planos de suplementação de glutamina' ${ }^{1}, \%$} & \multirow{3}{*}{ Valor $\mathrm{p}$} & \multirow{3}{*}{$\mathrm{CV}, \%$} \\
\hline & 0,0 & 0,$5 ; 0,0$ & 1,$0 ; 0,0$ & 1,$0 ; 0,5 ; 0,0$ & 1,$0 ; 1,0 ; 0,5 ; 0,0$ & & \\
\hline & \multicolumn{5}{|c|}{ um a 21 dias } & & \\
\hline Peso inicial, $\mathrm{g}$ & 46,00 & 46,20 & 44,20 & 43,75 & 44,50 & - & - \\
\hline Peso corporal, g & 587,68 & 602,43 & 570,95 & 584,13 & 610,65 & 0,474 & 5,51 \\
\hline Ganho de peso, g & 541,68 & 556,23 & 526,75 & 540,38 & 566,15 & 0,474 & 5,96 \\
\hline Consumo de ração, $g$ & $981,84^{\mathrm{ab}}$ & $918,26^{b}$ & $951,58^{\mathrm{b}}$ & $1133,08^{\mathrm{a}}$ & $1156,35^{\mathrm{a}}$ & 0,013 & 8,42 \\
\hline Conversão alimentar, g & 1,84 & 1,66 & 1,83 & 2,11 & 2,05 & 0,064 & 10,30 \\
\hline \multirow[t]{2}{*}{ Viabilidade produtiva, \% } & 94,92 & 96,52 & 95,65 & 94,56 & 95,65 & 0,818 & 4,88 \\
\hline & \multicolumn{5}{|c|}{ um a 42 dias } & & \\
\hline Peso corporal, g & $2111^{b}$ & $2220^{\mathrm{b}}$ & $2381^{\mathrm{ab}}$ & $2033^{b}$ & $2994^{a}$ & 0,011 & 13,47 \\
\hline Ganho de peso, g & $2066^{b}$ & $2174^{b}$ & $2337^{\mathrm{ab}}$ & $1989^{b}$ & $2950^{a}$ & 0,011 & 13,74 \\
\hline Consumo de ração, $g$ & 3608 & 3604 & 3556 & 3794 & 3967 & 0,418 & 6,99 \\
\hline Conversão alimentar, g & $1,76^{\mathrm{ab}}$ & $1,69^{\mathrm{abc}}$ & $1,54^{\mathrm{bc}}$ & $1,92^{\mathrm{a}}$ & $1,35^{c}$ & 0,011 & 10,49 \\
\hline Viabilidade produtiva, $\%$ & 90,58 & 89,57 & 92,17 & 89,13 & 94,56 & 0,881 & 7,13 \\
\hline
\end{tabular}

Médias dentro de uma linha seguidas de letras minúsculas iguais não diferem pelo teste de Tukey $(p>0,05)$. CV= Coeficiente de variação. ${ }^{1} P l a n o s$ de suplementação com a utilização do produto composto de $95 \%$ de L-glutamina $+5 \%$ de L-ácido glutâmico: $(0,0 \%)=$ sem suplementação de glutamina. $(0,5 ; 0,0 \%)=$ suplementação de $0,5 \%$ de glutamina de um a 7 dias e $0 \%$ de 8 a 42 dias. $(1,0 ; 0,0 \%)=$ suplementação de $1,0 \%$ de glutamina de um a 7 dias e $0 \%$ de 8 a 42 dias. $(1,0 ; 0,5 ; 0,0 \%)=$ suplementação de $1,0 \%$ de glutamina de um a 7 dias, $0,5 \%$ de 8 a 14 dias e $0,0 \%$ de 15 a 42 dias. $(1,0 ; 1,0 ; 0,5 ; 0,0 \%)=$ suplementação de $1,0 \%$ de glutamina de um a 14 dias, $0,5 \%$ de 15 a 21 dias e $0,0 \%$ de 22 a 42 dias.

Aos 7, 14 e 21 dias foi retirada uma ave e aos 42 dias de idade foram retiradas duas aves por repetição, cujo peso correspondeu a $\pm 10 \%$ do peso médio da unidade experimental. As aves retiradas foram submetidas a jejum de 8 horas, abatidas por deslocamento cervical seguido pelo processo de sangria, depenadas e evisceradas para avaliação dos pesos relativos de órgãos (proventrículo, moela, intestino, baço e bolsa cloacal) e das características de carcaça, sendo determinados os pesos absolutos e relativos de carcaça e cortes (peito, coxa+sobrecoxa, asas, dorso, cabeça+pescoço, pés). Os pesos relativos dos órgãos, pés e cabeça+pescoço foram determinados em relação ao peso da ave antes do abate. Os pesos relativos dos cortes foram calculados em relação ao peso da carcaça eviscerada.

Os dados foram submetidos à análise de covariância, utilizando o PROC GLM do SAS, versão 9.1, e quando ocorreram diferenças significativas às médias foram comparadas pelo teste de Tukey a $5 \%$ de probabilidade. O peso inicial foi considerado como covariável no modelo estatístico.

\section{RESULTADOS E DISCUSSÃO}

Os planos de suplementação de glutamina não influenciaram $(p>0,05)$ o desempenho de frangos de corte de um a 21 dias, exceto para consumo de ração em que os maiores $(p<0,05)$ consumos foram obtidos pelas aves submetidas aos planos de suplementação de 1,0; 0,$5 ; 0,0 \%$ e 1,$0 ; 1,0 ; 0,5 \%$ de glutamina nos períodos de 1 a 7,8 a 14 e 15 a 21 dias, respectivamente (tabela II). Todavia, estes tratamentos não diferiram do grupo controle.

Os valores obtidos para as variáveis de desempenho foram inferiores aos preconizados para a linhagem, conforme Cobb Vantress (2015) para peso corporal $(971 \mathrm{~g})$, consumo de ração (1.228 g) e conversão alimentar $(1,27)$. Possivelmente, o desempenho das aves, no presente estudo, não alcançou os valores sugeridos para a linhagem Cobb ${ }^{\circledR}-500$ devido as temperaturas ambientais elevadas registradas durante o período experimental que podem ter causado alterações fisiológicas nas aves, refletindo negativamente no desempenho.

Segundo Macari et al. (2002), o estresse por calor pode alterar a morfologia intestinal e, consequentemente, a capacidade de digestão e absorção dos nutrientes pelas aves, fato que pode ter prejudicado a eficiência de utilização dos nutrientes das dietas no presente estudo. Além disso, o baixo ganho de peso e a pior conversão alimentar obtidos podem estar relacionados ao gasto energético para manter a homeostase térmica, ocorrendo aumento da exigência de energia de mantença.

Embora não se tenha constatado efeitos positivos da glutamina sobre o desempenho das aves de um aos 21 dias de idade no presente estudo, Zavarize et al. (2011) concluíram que a inclusão de $1,0 \%$ de glutamina no período de um a 21 dias de idade favorece o desempenho de frangos de corte. Avellaneda et al. (2008), ao avaliar 0,$5 ; 1,0$ e $1,5 \%$ de aminogut ${ }^{\circledR}$ em dietas para frangos de corte de um a 25 dias de idade, observaram diminuição no consumo de ração, aumento no ganho de peso e, consequentemente, melhora na conversão alimentar com o nível de 1,5\%. Por outro lado, Maiorka et al. (2000) não obtiveram melhora no ganho do peso e conversão alimentar ao adicionar 1,0\% de glutamina na dieta de frangos de corte de um a sete dias de idade não desafiados.

Por sua vez, Olubodun et al. (2015) ao avaliarem o desempenho de frangos de corte sob temperaturas e 
Tabela III. Características de carcaça e de cortes de frangos de corte aos 42 dias submetidos a diferentes planos de suplementação de glutamina (Carcass and cuts characteristics of broilers at 42 days under different glutamine supplementation plans).

\begin{tabular}{|c|c|c|c|c|c|c|c|}
\hline \multirow{2}{*}{ Variáveis } & \multicolumn{5}{|c|}{ Planos de suplementação de glutamina ${ }^{1}, \%$} & \multirow{2}{*}{ Valor $\mathrm{p}$} & \multirow{2}{*}{$\mathrm{CV}, \%$} \\
\hline & 0,0 & 0,$5 ; 0,0$ & 1,$0 ; 0,0$ & 1,$0 ; 0,5 ; 0,0$ & 1,$0 ; 1,0 ; 0,5 ; 0,0$ & & \\
\hline Carcaça, g & $1.426^{\mathrm{ab}}$ & $1.445^{\mathrm{ab}}$ & $1.462^{\mathrm{ab}}$ & $1.367^{\mathrm{b}}$ & $1.607^{\mathrm{a}}$ & 0,022 & 11,54 \\
\hline Peito, g & $465,14^{\mathrm{ab}}$ & $448,07^{\mathrm{ab}}$ & $468,36^{\mathrm{ab}}$ & $420,17^{b}$ & $532,17^{a}$ & 0,029 & 17,57 \\
\hline Coxa+sobrecoxa, g & 439,86 & 446,21 & 449,71 & 430,83 & 484,17 & 0,177 & 11,60 \\
\hline Asas, $\mathrm{g}$ & 163,86 & 165,07 & 166,86 & 160,08 & 175,17 & 0,168 & 8,83 \\
\hline Dorso, $g$ & $344,14^{b}$ & $371,64^{\mathrm{ab}}$ & $371,64^{\mathrm{ab}}$ & $352,92^{\mathrm{b}}$ & $411,67^{a}$ & 0,030 & 13,79 \\
\hline Pés, g & 88,64 & 91,00 & 89,29 & 84,41 & 94,58 & 0,261 & 12,46 \\
\hline Cabeça+pescoço, g & 231,93 & 242,93 & 244,71 & 226,42 & 257,25 & 0,182 & 13,71 \\
\hline Gordura abdominal, g & 21,64 & 25,31 & 23,46 & 30,00 & 31,10 & 0,275 & 42,06 \\
\hline Carcaça, \% & $70,50^{\mathrm{ab}}$ & $69,92^{\mathrm{ab}}$ & $71,16^{\mathrm{ab}}$ & $68,92^{b}$ & $71,90^{a}$ & 0,014 & 1,95 \\
\hline Peito, \% & 32,38 & 30,65 & 31,51 & 30,74 & 32,66 & 0,367 & 9,92 \\
\hline Coxa+sobrecoxa, \% & 30,94 & 30,96 & 30,92 & 31,51 & 30,37 & 0,480 & 4,82 \\
\hline Asas, \% & 11,54 & 11,51 & 11,61 & 11,72 & 11,09 & 0,374 & 6,67 \\
\hline Dorso, \% & 24,31 & 25,79 & 25,55 & 25,77 & 25,68 & 0,332 & 8,74 \\
\hline Pés, \% & 6,26 & 6,34 & 6,19 & 6,18 & 5,96 & 0,870 & 10,98 \\
\hline Cabeça+pescoço, \% & 16,33 & 16,99 & 17,02 & 16,59 & 16,25 & 0,9056 & 13,65 \\
\hline Gordura abdominal, \% & 1,56 & 1,76 & 1,59 & 2,18 & 1,96 & 0,226 & 41,88 \\
\hline
\end{tabular}

Médias dentro de uma linha seguidas de letras minúsculas iguais não diferem pelo teste de Tukey $(p>0,05)$. CV $=C o e f i c i e n t e$ de variação. ${ }^{1} P l a n o s$ de suplementação com a utilização do produto composto de $95 \%$ de L-glutamina+5\% de L-ácido glutâmico: $(0,0 \%)=$ sem suplementação de glutamina. $(0,5 ; 0,0 \%)=$ suplementação de $0,5 \%$ de glutamina de um a 7 dias e $0 \%$ de 8 a 42 dias. $(1,0 ; 0,0 \%)=$ suplementação de $1,0 \%$ de glutamina de um a 7 dias e $0 \%$ de 8 a 42 dias. $(1,0 ; 0,5 ; 0,0 \%)=$ suplementação de $1,0 \%$ de glutamina de um a 7 dias, $0,5 \%$ de 8 a 14 dias e $0,0 \%$ de 15 a 42 dias. $(1,0 ; 1,0 ; 0,5 ; 0,0 \%)=$ suplementação de $1,0 \%$ de glutamina de um a 14 dias, $0,5 \%$ de 15 a 21 dias e $0,0 \%$ de 22 a 42 dias.

umidades cíclicas elevadas, verificaram que a inclusão de 0,5 e $1,0 \%$ de aminogut $\AA$ as dietas proporcionou aumento do ganho de peso e peso e melhora da conversão alimentar de um aos 21 dias de idade. E de modo similar ao deste estudo, os pesquisadores constataram que as aves também não alcançaram o desempenho estabelecido para a linhagem Cobb $®-500$ devido as temperaturas ambientais elevadas no transcorrer do estudo. Os planos de suplementação de glutamina influenciaram o desempenho das aves no período de um a 42 dias de idade (tabela II). Verificou-se que os frangos de corte suplementados com 1,0\% de glutamina de um a 14 dias, com $0,5 \%$ de glutamina de 15 a 21 dias e $0,0 \%$ de glutamina de 22 a 42 dias de idade apresentaram maiores $(\mathrm{p}<0,05)$ peso corporal e ganho de peso. Porém, o peso corporal e o ganho de peso desse tratamento não diferiu em relação ao plano de suplementação com 1,0\% de glutamina de um a 7 dias e $0 \%$ de 8 a 42 dias.

Constatou-se também que os frangos de corte suplementados com $1,0 \%$ de glutamina de um a 14 dias, com $0,5 \%$ de glutamina de 15 a 21 dias e $0,0 \%$ de glutamina de 22 a 42 dias de idade apresentaram melhor $(p<0,05)$ conversão alimentar, mas sem diferir do plano de suplementação com $0,5 \%$ de glutamina de um a 7 dias, com $0 \%$ de 8 a 42 dias e do plano com 1,0\% de glutamina de um a 7 dias e $0 \%$ de 8 a 42 dias. Por outro lado, o consumo de ração e a viabilidade produtiva não foram influenciados $(p>0,05)$ pelos planos de suplementação com glutamina no período de um a 42 dias de idade.

Embora o consumo de ração obtido pelos frangos de corte submetidos aos planos de suplementação tenha sido inferior ao preconizado para a linhagem
Cobb $®-500$ para o período acumulado de um aos 42 dias de idade (5073 g), observou-se que a suplementação de glutamina favoreceu o peso final, o ganho de peso e a conversão alimentar de frangos de corte criados sob temperaturas ambientais elevadas. $\mathrm{O}$ baixo consumo de ração observado no presente estudo em relação a literatura pode ser justificado pelas temperaturas elevadas registradas durante o período experimental.

De modo similar aos resultados obtidos no presente estudo, Olubodun et al. (2015) verificaram que a inclusão de 0,5 e 1,0\% de aminogut $\AA$ as dietas de frangos de corte criados sob temperaturas e umidades elevadas, de um aos 42 dias de idade, proporcionaram melhora do desempenho das aves e concluíram que sua inclusão na dieta é benéfica para a produção.

O plano de suplementação de 1,0\% de glutamina de um a 14 dias, 0,5\% de glutamina de 15 a 21 dias e $0,0 \%$ de glutamina de 22 a 42 dias para frangos de corte proporcionou maior $(p<0,05)$ peso de carcaça, peso de peito, peso de dorso e rendimento de carcaça (tabela III). Contudo, não diferem estatisticamente dos planos com $0 \%$ de glutamina de um a 42 dias de idade; com $0,5 \%$ de glutamina de um a 7 dias e $0 \%$ de 8 a 42 dias; e com 1,0\% de glutamina de um a 7 dias e $0 \%$ de 8 a 42 dias. Esses resultados são coerentes com os valores observados para ganho de peso e peso final dos frangos de corte. Entretanto, os pesos e rendimentos de coxa+sobrecoxa, asas, pés, cabeça+pescoço e gordura abdominal não foram influenciados $(\mathrm{p}>0,05)$ pelos planos de suplementação de glutamina.

Segundo Souba et al. (1990) pode haver correlação positiva entre a concentração de glutamina livre e a 
Tabela IV. Pesos relativos (g:g) de órgãos de frangos de corte aos 7, 14, 21 e 42 dias, submetidos a planos de suplementação de glutamina (Relative weights (g:g) of broilers organs at 7, 14, 21 and 42 days, subject to glutamine supplementation plans).

\begin{tabular}{|c|c|c|c|c|c|c|c|}
\hline \multirow{2}{*}{ Variáveis } & \multicolumn{5}{|c|}{ Planos de suplementação de glutamina' ${ }^{1}, \%$} & \multirow{2}{*}{ Valor $\mathrm{p}$} & \multirow{2}{*}{$\mathrm{CV}, \%$} \\
\hline & 0,0 & 0,$5 ; 0,0$ & 1,$0 ; 0,0$ & 1,$0 ; 0,5 ; 0,0$ & 1,$0 ; 1,0 ; 0,5 ; 0,0$ & & \\
\hline \multicolumn{8}{|c|}{7 dias } \\
\hline Proventrículo & 1,00 & 1,01 & 0,94 & 0,94 & 1,02 & 0,248 & 8,5 \\
\hline Moela & 4,57 & 4,66 & 4,38 & 4,36 & 4,44 & 0,800 & 10,3 \\
\hline Intestino & $6,66^{\mathrm{ab}}$ & $6,75^{\mathrm{ab}}$ & $6,58^{\mathrm{ab}}$ & $6,16^{b}$ & $7,77^{\mathrm{a}}$ & 0,035 & 12,5 \\
\hline Baço & $0,05^{\mathrm{b}}$ & $0,08^{a}$ & $0,07^{\mathrm{ab}}$ & $0,07^{\mathrm{ab}}$ & $0,07^{\mathrm{ab}}$ & 0,004 & 18,4 \\
\hline Bolsa cloacal & 0,19 & 0,16 & 0,19 & 0,18 & 0,19 & 0,736 & 33,3 \\
\hline \multicolumn{8}{|c|}{14 dias } \\
\hline Proventrículo & 0,74 & 0,69 & 0,80 & 0,72 & 0,70 & 0,171 & 12,1 \\
\hline Moela & 3,83 & 3,43 & 3,81 & 3,51 & 3,67 & 0,299 & 10,7 \\
\hline Intestino & 5,91 & 5,84 & 5,88 & 5,84 & 5,32 & 0,839 & 19,4 \\
\hline Baço & 0,07 & 0,07 & 0,10 & 0,09 & 0,08 & 0,329 & 29,8 \\
\hline Bolsa cloacal & 0,24 & 0,23 & 0,28 & 0,25 & 0,24 & 0,679 & 27,9 \\
\hline \multicolumn{8}{|c|}{21 dias } \\
\hline Proventrículo & 0,64 & 0,64 & 0,69 & 0,73 & 0,60 & 0,362 & 18,1 \\
\hline Moela & 3,13 & 3,16 & 3,30 & 3,11 & 3,37 & 0,950 & 20,9 \\
\hline Intestino & 4,81 & 4,55 & 4,60 & 4,92 & 4,97 & 0,661 & 12,3 \\
\hline Baço & 0,10 & 0,08 & 0,10 & 0,10 & 0,10 & 0,602 & 30,5 \\
\hline Bolsa cloacal & 0,31 & 0,30 & 0,31 & 0,33 & 0,36 & 0,855 & 33,1 \\
\hline \multicolumn{8}{|c|}{42 dias } \\
\hline Proventrículo & 0,40 & 0,44 & 0,36 & 0,36 & 0,40 & 0,775 & 26,91 \\
\hline Moela & 1,89 & 1,98 & 1,93 & 2,13 & 1,80 & 0,197 & 12,31 \\
\hline Intestino & $3,31^{\mathrm{ab}}$ & $3,65^{\mathrm{a}}$ & $2,95^{\mathrm{ab}}$ & $3,51^{\mathrm{ab}}$ & $2,78^{b}$ & 0,021 & 14,10 \\
\hline Baço & 0,08 & 0,09 & 0,09 & 0,08 & 0,08 & 0,931 & 31,44 \\
\hline Bolsa cloacal & 0,18 & 0,19 & 0,20 & 0,14 & 0,17 & 0,628 & 42,15 \\
\hline
\end{tabular}

Médias dentro de uma linha seguidas de letras minúsculas iguais não diferem pelo teste de Tukey $(p>0,05)$. CV: Coeficiente de variação. ${ }^{1} P l a n o s$ de suplementação com a utilização do produto composto de $95 \%$ de L-glutamina+5\% de L-ácido glutâmico: $(0,0 \%)=$ sem suplementação de glutamina. $(0,5 ; 0,0 \%)=$ suplementação de $0,5 \%$ de glutamina de um a 7 dias e $0 \%$ de 8 a 42 dias. $(1,0 ; 0,0 \%)=$ suplementação de $1,0 \%$ de glutamina de um a 7 dias e $0 \%$ de 8 a 42 dias. $(1,0 ; 0,5 ; 0,0 \%)=$ suplementação de $1,0 \%$ de glutamina de um a 7 dias, $0,5 \%$ de 8 a 14 dias e $0,0 \%$ de 15 a 42 dias. $(1,0 ; 1,0 ; 0,5 ; 0,0 \%)=$ suplementação de $1,0 \%$ de glutamina de um a 14 dias, $0,5 \%$ de 15 a 21 dias e $0,0 \%$ de 22 a 42 dias.

taxa de síntese proteica no músculo esquelético, ou seja, quanto maior a concentração de glutamina circulante, maior a taxa de síntese de proteína. Todavia pesquisas como a de Pelícia et al. (2010) que avaliando a influência da suplementação de níveis de 0,04 a 0,07\% de glutamina+ácido glutâmico não observaram efeitos para as características de carcaça de frangos de corte.

O plano de suplementação de 0,5\% de glutamina de um até sete dias promoveu aumento $(p<0,05)$ dos pesos relativos de baço aos sete dias de idade, quando comparado aos demais planos de suplementação de glutamina para frangos de corte (tabela IV). Todavia, os pesos relativos de proventrículo, moela, intestino, bolsa cloacal e comprimento de intestino não diferiram ( $p>0,05)$ entre os planos de suplementação.

Poulin and Mouillot (2004) postularam que a presença de baços maiores nas aves pode ser um bom indicador da força da resposta imune deflagrada contra a invasão de parasitos e de sua capacidade de lidar com infecções potenciais. Moller and Erritzoe (2000) também indicam que aves com baços menores foram mais suscetíveis ao parasitismo por nematóides ao apresen- tarem capacidade de resposta imune debilitada em comparação àquelas que apresentam baços maiores.

Aos 14 e aos 21 dias de idade, os planos de suplementação de glutamina não influenciaram ( $p>0,05)$ os pesos relativos dos diversos órgãos avaliados. Entretanto, aos 42 dias de idade, a suplementação de 1,0\% de glutamina de um a 14 dias seguida da suplementação de $0,5 \%$ de glutamina de 15 a 21 dias e $0,0 \%$ de glutamina de 22 a 42 dias de idade resultou no menor peso relativo de intestino de frangos de corte, o que se deve, provavelmente, aos desvios na síntese proteica para deposição de músculo, uma vez que se obteve para o mesmo plano de suplementação o maior peso corporal, ganho de peso e peso absoluto de carcaça e de peito.

\section{CONCLUSÃO}

Para frangos de corte criados sob temperaturas elevadas, recomenda-se o plano de suplementação de $1,0 \%$ de glutamina até 14 dias, $0,5 \%$ de glutamina até 21 dias e $0,0 \%$ de 22 a 42 dias de idade, o qual pro- 
porciona maior peso corporal, ganho de peso, peso de carcaça, peito e rendimento de carcaça, apesar de não atingir o padrão de desempenho da genética.

\section{BIBLIOGRAFIA}

Avellaneda, Y.; Hernández, J.; Ariza, C. y Afanador, T. 2008. Efecto de la suplementación de L-glutamina y L-glutamato (Aminogut ${ }^{\circledR}$ ) sobre el crecimiento temprano de pollos de engorde. Rev Med Vet Zoot, 55: 77-90.

Cobb Vantress. 2015. Broiler performance and nutrition supplement. Performance objectives metric (males). Cobb-Vantress. Arkansas. http:// www.cobb-vantress.com/docs/default-source/cobb-500-guides/ Cobb500_Broiler_Performance_And_Nutrition_Supplement.pdf (18/08/2014).

Furtado, D.A.; Azevedo, P.V. e Tinôco, I.F.F. 2003. Análise do conforto térmico em galpões avícolas com diferentes sistemas de acondicionamento. Rev Bras Eng Agríc Ambient, 7: 559-564.

Macari, M.; Furlan, R.L. e Gonzales, E. 2002. Fisiologia aplicada a frango de corte, $2^{a}$ ed. Ed. Funep/Unesp. Jaboticabal. 375 pp.

Maiorka, A.; Silva, A.V.F.; Santin, E.; Borges, S.A.; Boleli, I.C. e Macari, M. 2000. Influência da suplementação de glutamina sobre o desempenho e o desenvolvimento de vilos e criptas do intestino delgado de frangos de corte. Arq Bras Med Vet Zoo, 52: 487-490.

Moller, A.P. and Erritzoe, J. 2000. Predation against birds with low immunocompetence. Oecologia, 122: 500-504.

Murakami, A.E.; Sakamoto, M.I.; Natali, M.R.M.; Souza, L.M.G. and Franco, J.R.G. 2007. Supplementation of glutamine and vitamin E on the morphometry of the intestinal mucosa in broiler chickens. Poultry Sci, 86: 488-495.

Newsholme, P. 2001. Why is L-glutamine metabolism important to cells of the immune system in health, postinjury, surgery or infection? J Nutr, 131: 2515-2522.
Olubodun, J.O.; Zulkifli, I.; Farjam, A.S.; Hair-Bejo, M. and Kasim, A. 2015. Glutamine and glutamic acid supplementation enhances performance of broiler chickens under the hot and humid tropical condition. Ital J Anim Sci, 14: 25-29.

Oliveira Neto, A.R.; Oliveira, R.F.M.; Donzele, J.L.; Rostagno, H.S.; Ferreira, R.A.; Maximiano, H.C. e Gasparino, E. 2000. Efeito da temperatura ambiente sobre o desempenho e características de carcaça de frangos de corte alimentados com dieta controlada e dois níveis de energia metabolizável. Rev Bras Zootecn, 29: 183-190.

Pelícia, V.C.; Sartori, J.R.; Zavarize, K.C.; Pezzato, A.C.; Stradiotti, A.C.; Araujo, P.C.; Mituo, M.A.O. and Madeira, L.A. 2010. Effect of nucleotides on broiler performance and carcass yield. Rev Bras Cienc Avic, 12: 31-34.

Poulin, R. and Mouillot, D. 2004. The relationship between specialization and local abundance: the case of helminth parasites of birds. Oecologia, 140: 372-378.

Rostagno, H.S.; Albino, L.F.T.; Donzele, J.L.; Gomes, P.C.; Oliveira, R.F.; Lopes, D.C.; Ferreira, A.S.; Barreto, S.L.T. e Euclides, R.F. 2011 . Tabelas brasileiras para aves e suínos: Composição de alimentos e exigências nutricionais. $3^{\mathrm{a}}$ ed. Ed. UFV. Viçosa. $252 \mathrm{pp}$.

Souba, W.W.; Herskowitz, K.; Salloum, R.M.; Chen, M.K. and Austgen, T.R. 1990. Gut glutamine metabolism. J Parenter Enter, 94: 45-50.

Yi, G.F.; Allee, G.L.; Knight, C.D. and Dibner, J.J. 2005. Impact of glutamine and oasis hatching supplement on growth performance, small intestinal morphology, and immune response of broilers vaccinated and challenged with Eimeria maxima. Poultry Sci, 84: 283-293.

Zavarize, K.C.; Sartori, J.R.; Pelícia, V.C.; Pezzato, A.C.; Araujo, P.C.; Stradiotti, A.C. e Madeira, L.A. 2011. Glutamina e nucleotídeos na dieta de frangos de corte criados no sistema alternativo. Arch Zootec, 60: $913-920$ 